\title{
26400 - EXTUBATION OF A DIFFICULT AIRWAY
}

Geoff Bellingham MD, Chris Harle, FRCA; London Health Sciences Centre - North Campus, London, ONTARIO, Canada 